\title{
The Effect of Green Tea (Camellia sinensis) Extract Against Hepato-Toxicity Induced By Tamoxifen in Rats \\ Faiza A Mahboub*
}

Biology Department, Faculty of Applied sciences, Umm Al-Qura University, Makkah Al-Mukaramah, Saudi Arabia

\begin{abstract}
The present study was conducted to elucidate the antioxidant capacity of green tea (Camellia sinensis) extract against Tamoxifen citrate-induced liver injury. Four groups containing ten female Wister rats each were selected: Group I, served as control group, Group II, permitted Green Tea Extract (1.5\% w/v in water) as the sole drinking fluid, Group III, injured by intraperitoneal injection of Tamoxefin ( $45 \mathrm{mg} / \mathrm{Kg} / \mathrm{day}$ ) for 7 successive days and Group IV, permitted green tea extract as a sole source of drinking water ( $1.5 \% \mathrm{w} / \mathrm{v}$ in water) 4 days prior and 14 days after Tamxifen-intoxication $(45 \mathrm{mg} / \mathrm{Kg} /$ day for 7 successive days). Hepatic oxidative damage was observed in Tamoxefin treated rats as evidenced via augmentation in liver lipid peroxidation as well as depletion in liver antioxidant enzymes; catalase, superoxide dismutase and glutathione peroxidase with highly degeneration and necrosis of the hepatocytes. Histopathological studies of liver treated with Tamoxefin revealed that supplementation of green tea extract resulted in mild degeneration and necrosis of the hepatocytes. Furthermore, green tea extract had normalized catalase, superoxide dismutase, glutathione peroxidase and liver lipid peroxidation content. In Conclusion, the supplementation of green tea extract appeared to be beneficial to a great extent in attenuating and restoring the damage sustained by Tamoxefin exposure.
\end{abstract}

Keywords: Green tea extract; Glutathione peroxidase; Malondialdehyde; Catalase; Superoxide dismutase; Liver; Tamoxifen

\section{Introduction}

Interest has increased in naturally-occurring antioxidants that can be used to protect human beings from oxidative stress damage [1] because natural antioxidant from plants (e.g. green tea) is generally recognized as safe in the form of extract. Green tea polyphenols and epigallocatechin-3-gallate (EGCG) have potent chemo preventive and therapeutic effect against numerous cancers of skin, lung, breast, colon, liver, stomach and prostate [2]. P-glycoprotein activity, which is responsible for the chemotherapy drugs resistance could be overcome green tea polyphenols [3]. Green tea catechins was reported to modulate cell signaling pathways associated with angiogenesis, metastasis and invasion including the inhibition of vascular endothelial growth factor as well as the inhibition of matrix metallo-proteinases [4]. EGCG has an antioxidant activity about 25 and 100 times greater than that of vitamins $\mathrm{E}$ and $\mathrm{C}$, respectively, and is the most potent of all the catechins [5]. EGCG, as a natural product has enormous potential to be an anticancer agent capable of enhancing tumour cell sensitivity to therapy [6]. Anticipate that the combination of green tea catechins and anticancer drugs will be an effective strategy to enhance the therapeutic effects and reduce the adverse effects of anticancer drugs in cancer patients [7].

In animal studies [8] revealed that green tea may protect liver and brain cells against sequel of oxidative stress induced by ethanol intoxication. EGCG has synergistic effect against TAM and breast cancer cells; it induced apoptosis and may impart its anti-cancer property through unique mechanism acting on ERa signal transduction [9].

Potent mechanism received considerable attention; EGCG can modulate gene expression by influencing epigenetic processes such as DNA methylation and/or histone modification [10]. Tamoxifen citrate (TAM), 1-[4-(2-dimethyl-aminoethoxy) phenyl]-1,2-diphenyl1-butene), is nonsteroidal antiestrogen drugs used for the treatment and prevention of all stages of hormone-dependent breast cancer [11]. TAM in high dose is liver carcinogen in rats [12] due to oxygen radical overproduction, which occurs during TAM metabolism. Williams et al. [13] conclude that TAM which is used in the treatment of breast cancer has a strong hepatocarcinogenic effect as shown in their results
[13]. Experimental trials suggest a synergistic interaction of green tea catechins with tamoxifen or raloxifene in the treatment of estrogen receptor-positive and estrogen receptor-negative breast cancer through estrogen receptor-dependent and -independent mechanisms [14]. EGCG induces various cellular actions by functioning as an antioxidant, a prooxidant, and an iron chelator [15]. This study was conducted to gain insight on the histopathological, biochemical and antioxidant profile exerted upon GTE supplementation to the TAM -induced liver injured rats.

\section{Materials and Methods}

In this study, forty adult female albino rats, weighing 120-170 g. were used as experimental animals. They were kept in wire-floored cages under standard laboratory conditions of $12 \mathrm{~h} / 12 \mathrm{~h}$ light/dark, 25 $\pm 2^{\circ} \mathrm{C}$ with free access of food and water. The Green tea extract was made according to Maity et al. [16]. The maintenance of the animals was in full compliance with the standard laboratory animals care protocols approved by Animal Care and Use Committee.

The rats were randomly divided into 4 groups of 10 animals each as follows:

Group 1: Normal control untreated rats. Group II: TAM-intoxicated rats in a dose of ( $45 \mathrm{mg} / \mathrm{Kg} /$ day) i.p., for 7 successive days [17]. Group III: GTE rats, permitted $1.5 \%$ green tea extract (GTE) as their sole source of drinking water for 21 days. Group IV: TAM + GTE rats, permitted GTE as a sole source of drinking water $(1.5 \% \mathrm{w} / \mathrm{v}$ in water)

*Corresponding author: Faiza A Mahboub, Biology Department, Faculty of Applied sciences, Al-Sulaimaniah, Al Zamakhshari St. Jeddah, West 12183/21473, Umm Al-Qura University, Makkah Al-Mukaramah, Saudi Arabia, Tel: 00966505522517 Fax: 0096626296879; E-mail: faizamahboub11@hotmail.com

Received September 23, 2016; Accepted October 12, 2016; Published October 17, 2016

Citation: Mahboub FA (2016) The Effect of Green Tea (Camellia sinensis) Extract Against Hepato-Toxicity Induced By Tamoxifen in Rats. J Food Process Technol 7 625. doi: $10.4172 / 2157-7110.1000625$

Copyright: (c) 2016 Mahboub FA. This is an open-access article distributed under the terms of the Creative Commons Attribution License, which permits unrestricted use, distribution, and reproduction in any medium, provided the original author and source are credited. 
Citation: Mahboub FA (2016) The Effect of Green Tea (Camellia sinensis) Extract Against Hepato-Toxicity Induced By Tamoxifen in Rats. J Food Process Technol 7: 625. doi: 10.4172/2157-7110.1000625

Page 2 of 5

4 days prior and 14 days after TAM-intoxication $(45 \mathrm{mg} / \mathrm{Kg} /$ day for 7 successive days).

After 25 days, control and treated animals were subjected to light ether anesthesia and killed by cervical dislocation. The abdomen excision and liver removal was done immediately by dissection, washed in ice-cold isotonic saline and blotted between two filter papers. The liver divided into two parts, the first part was wrapped in aluminum foil and stored at $-80^{\circ} \mathrm{C}$. A $10 \%(\mathrm{w} / \mathrm{v})$ liver homogenates was prepared in ice-cold 0.1 M potassium phosphate buffer, $\mathrm{PH} 7.5$ using Branson sonifier (250, VWR Scientific, USA). Fresh aliquot from liver homogenate was used to estimate, glutathione peroxidase (GPX) [18], catalase (CAT) [19], superoxide dismutase (SOD) [20] and Malondialdehyde (MDA) [21]. The second part, fixed at room temperature overnight in $10 \%$ formalin solution then process to be stained routinely with haematoxylin and Eosin [22]. The values are expressed as mean \pm SE. The results were computed statistically using statistical package for social science (SPSS software package, version 15) using one-way analysis of variance (ANOVA). Post hoc testing was performed for inter-group comparison on using the least significant digit (LSD). $\mathrm{P}<0.05$ was considered as significant [23].

\section{Results}

In Table 1, the TAM intoxication resulted in a state of liver injury oxidative stress in rats as manifested by the significant declines in GPX,
CAT and SOD enzyme levels and increase in MDA level by $\mathrm{p}<0.001$, respectively compared to the control. Administration of GTE alone showed non-significant changes in GPX, CAT, SOD enzyme levels and MDA level compared to control rats. Moreover, GTE supplementation to TAM-intoxicated rats showed significant improvement to the activities of antioxidant enzymes such as GPX, SOD and CAT as well as the level of MDA, compared to TAM intoxicated liver injured rats.

Light micrographs revealed that the structural components of the liver in both control and GTE respectively showed normal hepatic cyto-architecture. They formed of polyhedral hepatocytes which are radically arranged in anatomizing and branching plates separated by vascular blood sinusoids (Figures 1 and 2). Hepatocytes may contain one central nucleus (monoucleated) or two nuclei (binucleated) with prominent nucleolus. The blood sinusoid is lined with endothelial all and contains many triangle kupffer cells (Figures 3 and 4).

After TAM treatment, the inspection of liver sections showed degeneration and coagulative necrosis in hepatocytes. They demonstrated the presence of cellular infiltration and dilatation of blood sinusoid with diffuse Kupffer cells proliferation in between the hepatocytes (Figure 5). The hepatocytes have vesiculated nuclei and different stages of karyolysis ranging from pale nuclei to completely disappeared one with stasis of blood in both central vein and sinusoids (Figure 6). Histopathological examination of liver sections of TAM +

\begin{tabular}{|c|c|c|c|c|}
\hline \multirow{2}{*}{ Parameter } & \multicolumn{3}{|c|}{ Experimental groups } \\
\cline { 2 - 4 } & Control & T & \multicolumn{1}{|c|}{$\boldsymbol{p}$} \\
\hline MDA (nmol/g protein) & $63.20 \pm 4.36$ & $118.20^{\mathrm{a}} \pm 6.40$ & $65.0 \pm 6.32$ & $98.80^{\mathrm{ab}} \pm 5.54$ \\
\hline CAT (U/L) & $33.40 \pm 4.66$ & $15.20^{\mathrm{a}} \pm 1.98$ & $34.60 \pm 3.19$ & $22.80^{\mathrm{b}} \pm 4.64$ \\
\hline GPx (U/L) & $41.80 \pm 3.65$ & $21.20^{\mathrm{a}} \pm 2.63$ & $48.20 \pm 3.37$ & $35.60^{\mathrm{b}} \pm 3.16$ \\
\hline SOD (U/L) & $54.80 \pm 4.58$ & $26.20^{\mathrm{a}} \pm 3.25$ & $52.40 \pm 3.66$ \\
\hline
\end{tabular}

Data are presented as means $\pm S E,(n=8)$.

a Significant difference as compared to control group $(P<0.05)$.

b Significant difference as compared to tamoxifen group $(P<0.05)$

*Statistically significant at $P<0.05$.

$P: p$ value for $F$ test (ANOVA) for comparison between the different studied groups.

Table 1: Effect of TAM alone and in combination with GTE on the level of MDA and the activities of CAT, SOD and GPX in liver homogenate of female rats.

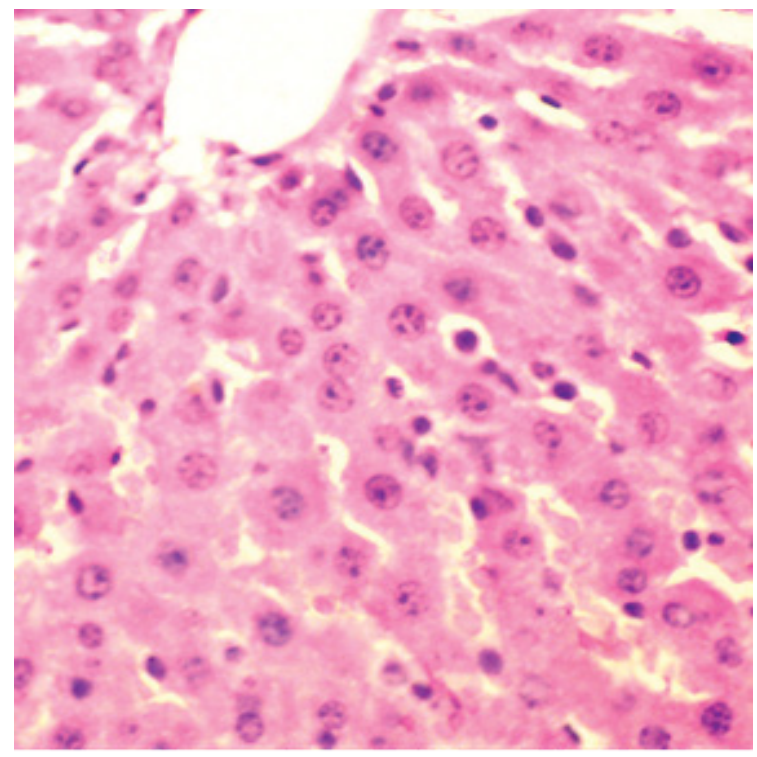

Figure 1: Light micrographs of control liver showing, central vein (CV), sinusoids in-between hepatocytes strands (S) and Kupffer cells (arrows) (H\&E, 100X).

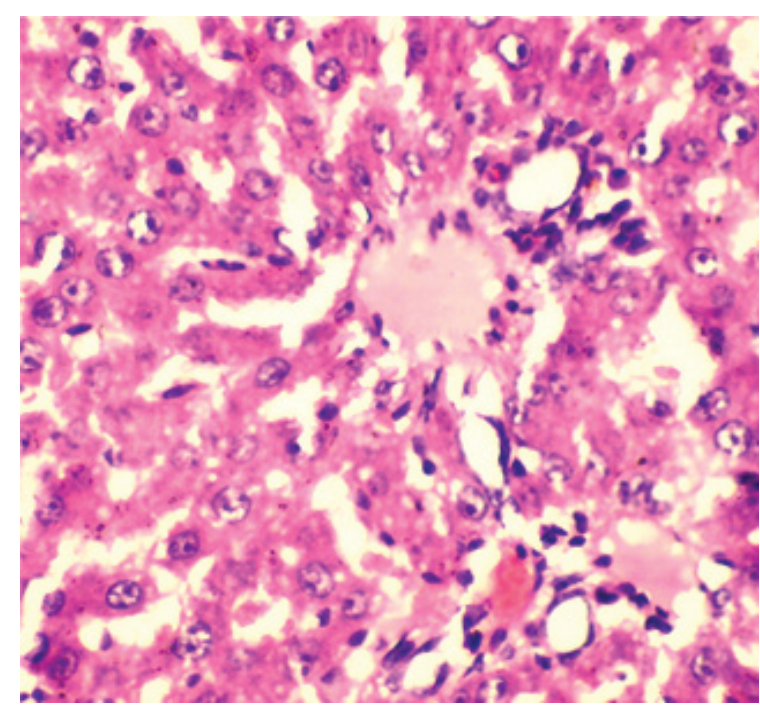

Figure 2: Light micrographs of TAM-treated liver showing, inflammatory cells infiltration in the portal area (star) with diffuse Kupffer cells proliferation in between the degenerated hepatocytes (arrows), dilatation and congestion in both the sinusoids (S) and the central vein (CV) (H\&E, 100X). 
Citation: Mahboub FA (2016) The Effect of Green Tea (Camellia sinensis) Extract Against Hepato-Toxicity Induced By Tamoxifen in Rats. J Food Process Technol 7: 625. doi: 10.4172/2157-7110.1000625

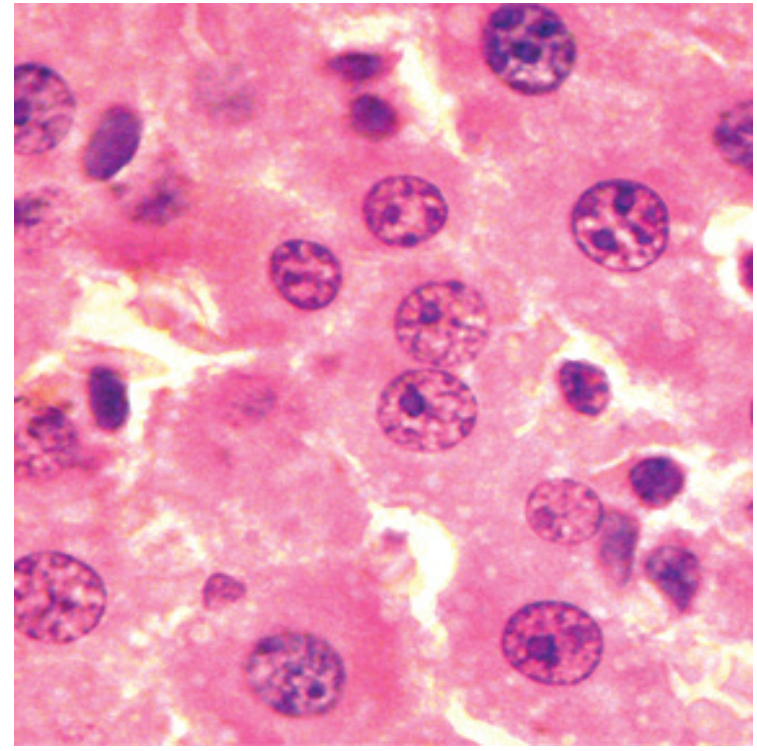

Figure 3: Enlarged part from figure 1, showing polyhedral hepatocytes $(\mathrm{H})$ with one central nucleus or two nuclei $(\mathrm{N})$, sinusoid $(\mathrm{S})$ contains Kupffer cell $(\mathrm{K})$ and lined with endothelial cell (arrow) (H\&E, 1000X)

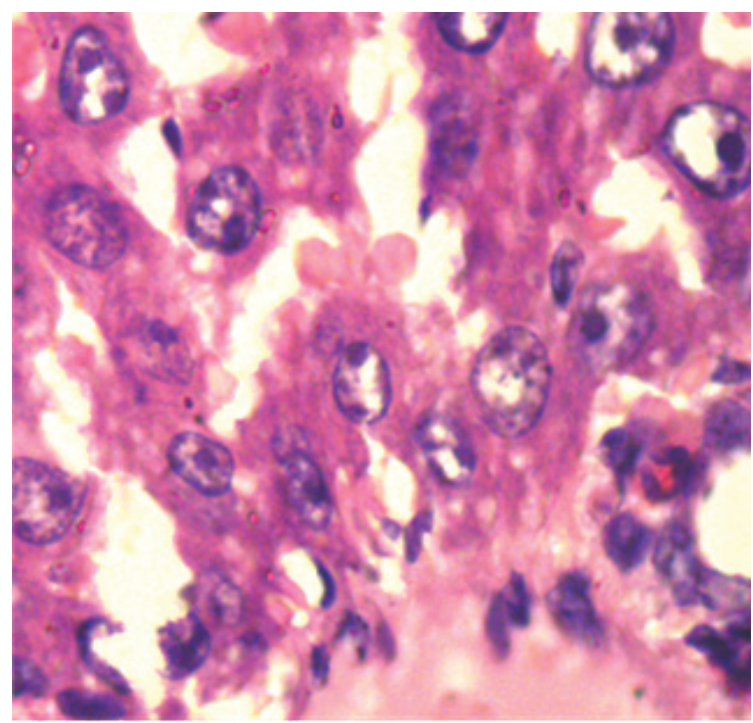

Figure 4: Enlarged part from figure 3 showing, degenerated hepatocytes with vesiculated nuclei $(\mathrm{N})$ and different stages of karyolysis (arrows) ranging from pale nuclei to completely disappeared one (H\&E, 1000X).

GTE demonstrated marked improvement in its histological structure in comparison to the TAM- group with less pathological changes (Figure 7). Blood sinusoids were less dilated and bordered by polyhedral hepatocytes with central basophilic nuclei (Figure 8).

\section{Discussion}

It was obvious that TAM in toxic doses elucidated to be a hepatocarcinogen in rats [24] this refers to its high affinity to hepatic tissue [25]. It revealed that production of five DNA adducts in rat liver was responsible for carcinogenesis [26]. The results in this study indicated that TAM inhibited SOD, CAT and GPX activities in liver of rat where decrease in antioxidant defenses in the liver was due to liver damage [27]. This depletion may be due to the decreased synthesis of enzymes or

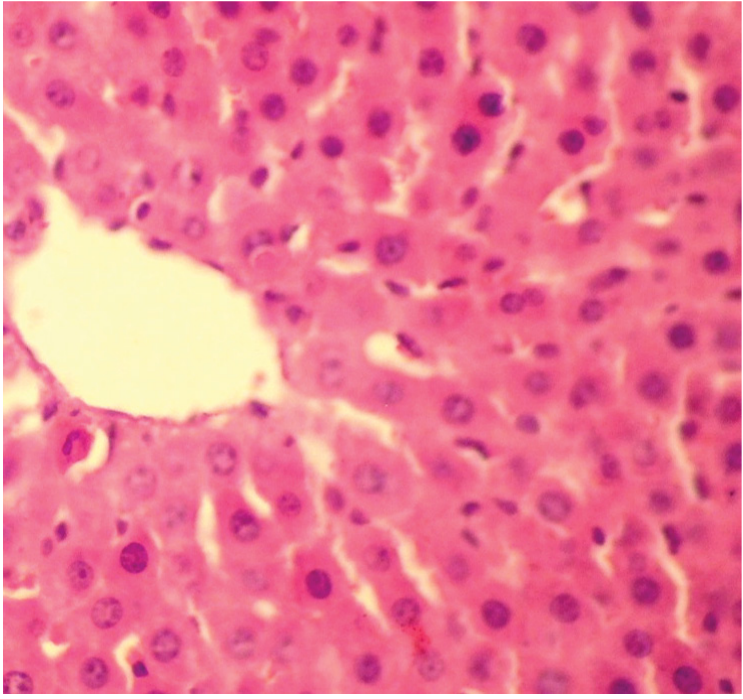

Figure 5: Light micrographs of GTE- liver showing normal hepatic cytoarchitecture (H\&E, 100X).

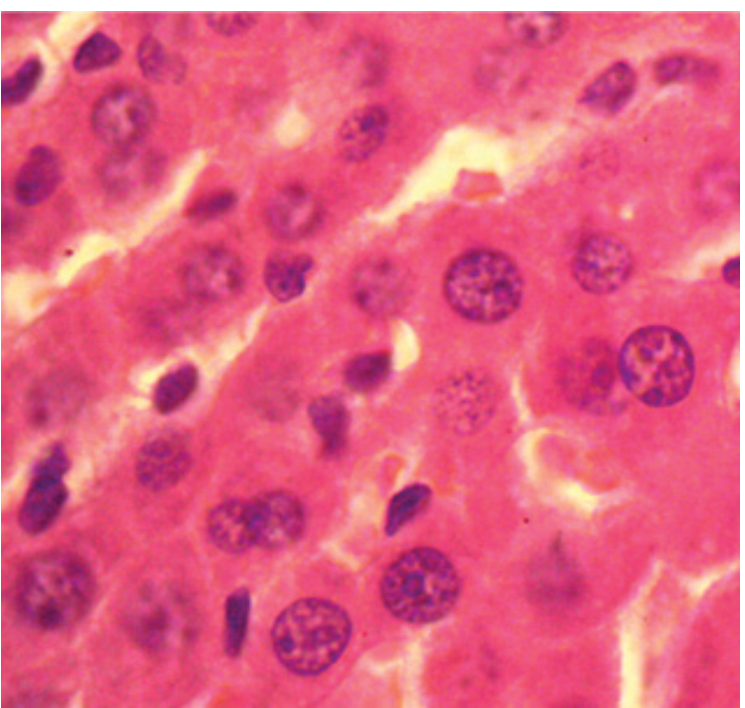

Figure 6: Light micrographs of GTE- liver, showing enlarged part from figure 5 (H\&E, 1000X)

oxidative inactivation of enzyme protein as occurred in kidney treated with Cyromazine and/or Chlorpyrifos [28]. The decrease in antioxidant defense systems of TAM intoxicated rats render them more susceptible to hepatotoxicity [29]. Also the activities of intracellular antioxidant enzymes decreased with the increase of lipid peroxidation levels [30] GPX is responsible about destruction and degradation of phospholipids hydroperoxides and this suggested being a pathway of cytoprotection against the deleterious effects of phospholipids hydroperoxides. The decreased GPX level of TAM intoxicated rats, leads to an increase of toxic level to the cells, the oxidation process resulted as a result of TAM intoxication leads to release of iron ions. These ions, therefore, become more reactive in liver. Free irons ions participate in generation of hydroxyl radicals which are the most active reactive oxygen species (ROS) and they react readily with most cellular components [8]. TAM leads to induction of lipid peroxidation these results are compatible with previous researchers following OPIs administration [31]. Indeed, the antioxidant enzymes SOD, GPX and CAT act as radical scavenger 


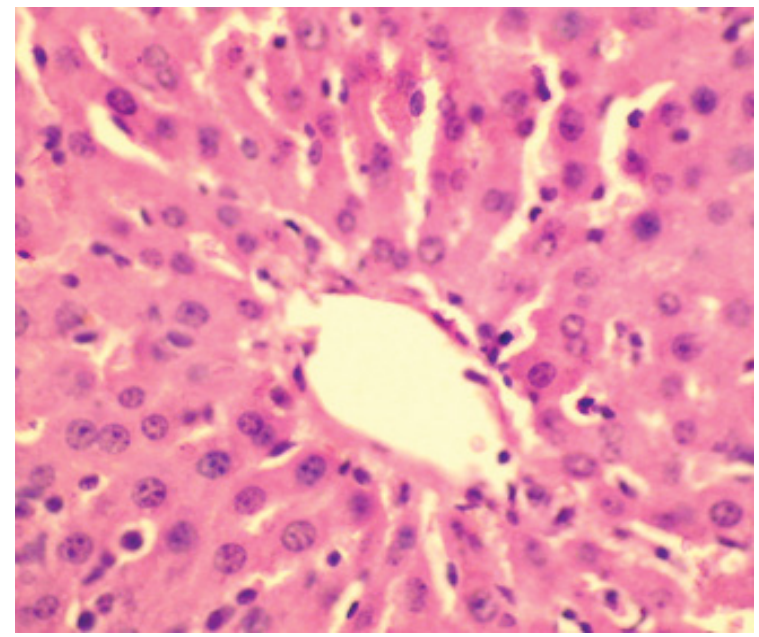

Figure 7: Light micrographs of TAM + GTE -treated liver showing, less diffuse Kupffer cells between the improved hepatocytes (arrows), less dilatation in the sinusoids (S) and central vein (CV) (H\&E, 100X).

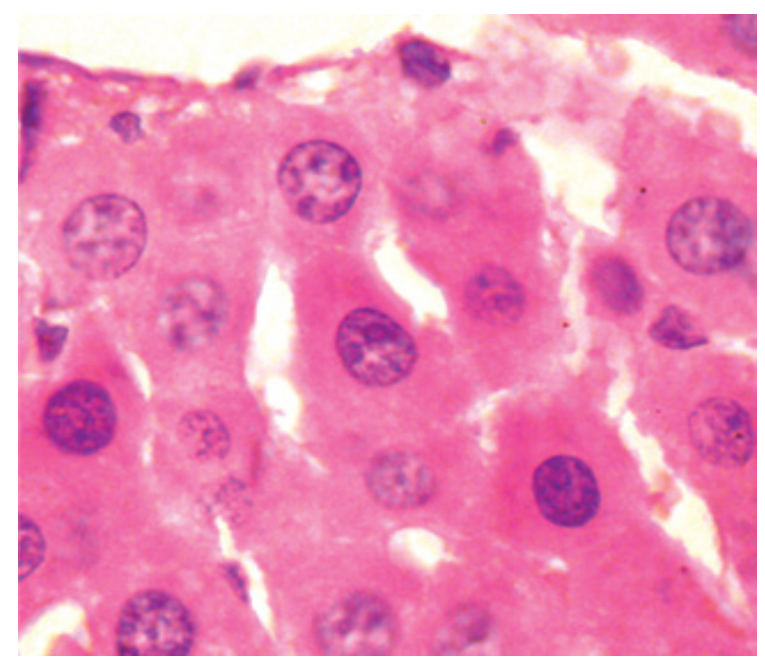

Figure 8: Light micrographs of TAM+ GTE -treated liver showing, hepatocytes radiating from central vein $(\mathrm{CV})$ with central nuclei $(\mathrm{N})$ and few karyolitic one (arrows) (H\&E, 100X).

by limiting the effects of oxidant molecules in tissues therefore defend against oxidative cell injury [32]. The loss of cell function under oxidative stress conditions refers to accumulation of lipid peroxide [33]. This explains the histopathological alterations in the present study which could be summarized as follows: degeneration and coagulative necrosis in the hepatocytes, inflammatory cells infiltration, and Kupffer cells proliferation in TAM-treated group which sustained the leakage of liver enzymes. This study illustrates most of biochemical alterations accompanied histopathological changes were alleviated following GTE administration [34]. This attributed to the antioxidant capacity of GTE that reduce the lipid peroxidation and leading to restore the integrity of the cell membrane and improve the disturbance in permeability [28] as GTE has a role in alleviating the oxidative stress status produced after TAM-intoxication in female rats that resulted in liver injury due to involvement of oxidant mechanisms [35].

In correspondence with the data obtained from this study, Hesham [36] speculated $1.5 \%$ GTE has the capacity to scavenge free radical and protects against oxidative stress induced by TAM intoxication.
Hence, the possible of hepatoprotection of GTE extract mechanism may be attributed to polyphenolic compounds (e.g. epicatechins), that scavenge a wide range of free radicals including the most active hydroxyl radical, which initiate lipid peroxidation [37]. Therefore, it decreases the concentration of lipid free radicals [38]. It was reported previously that phenolic compounds chelate metal ions, especially iron and copper inhibit the generation of hydroxyl radicals and degradation of lipid hydroperoxides [37]. Epicatechins (antioxidant present in green tea) are effective scavengers of physiologically active reactive oxygen and nitrogen species including superoxide [39] and peroxynitrite [40]. It prevents the loss of lipophilic antioxidant $\alpha$-tocopherol, by repairing tocopheryl radicals and protection of the hydrophilic antioxidant ascorbate [38]. In this study the levels of antioxidant enzyme activities in liver homogenates (GPX, SOD and CAT) and MDA were significantly improved upon treatment of TAM-intoxicated rats with 1.5\% GTE which inhibited TAM-induced hepatic injury and thereby the level of oxidative stress as it can decrease lipid peroxidation and enhance antioxidant enzyme activities, On the contrary, Oge et al. [41] showed that CAT did not show any significant difference after TAM intoxication. In agreement with the results obtained in this study, Ostrowska et al. [8] stated that the administration of green tea to ethanol-intoxicated rats, resulted in the normalization of lipid peroxidation as well as glutathione concentration and GPX activities in liver. The increase in GPX and SOD activities after GTE administration to TAM intoxicated rats, was attributed to induction or mutually protective interactions especially superoxide dismutase, which present at low level only but highly inducible under oxidative stress [42].

Tea contains minerals act as co-factors in antioxidant enzymes: zinc, selenium and manganese. Additional mechanisms for Polyphenols in which they minimize oxidation level besides direct role as antioxidants: (1) Binding of metal ions such as iron and copper and prevents its participation in oxidation reactions (leading to the formation of hydroxyl radical). (2) Prevention of redox sensitive transcription factors activation that amongst others things serve as mediators of inflammatory reactions. (3) Suppression of oxidation stimulants such as induced nitric oxide synthase (iNOS), cyclooxygenase 2 (COX-2), lipoxygenase 2 (LOX-2) and xanthine oxidase. Induction of antioxidant enzymes such as glutathione S-transferase and super oxide dismutase [43]. The aqueous extract of green tea has an efficient protection against arsenic which induces biochemical toxicity in experimental rats, these results compatible with ours in this research [44]. Also TAM would cause hepatotoxicity at the early stage of endocrine treatment in mice, and the underlying mechanism was involved with hepatocyte apoptosis [45].

\section{Conclusion}

The data achieved from this study revealed that, TAM induced oxidative damage and hepatotoxicity in rats. In contrast, the oral supplementation of $1.5 \%$ GTE to TAM- intoxicated rats, exerted an improvement against TAM-induced which caused liver injury that was clearly obvious in the structural integrity of cell membrane and eventually alleviates the histopathological changes as well as the biochemical perturbations, as it has beneficial effects on damaged liver cells to prevent lipid peroxidation and improve antioxidant enzyme activities. Based on the present observations, it was proposed that GT may provide a cushion for prolonged therapeutic option against toxinsinduced hepatotoxicity without harmful side effects. Information on potential synergistic or antagonistic interactions between the constituents of green tea and other chemicals, particularly metals, will lead to a clearer and better understanding of the potential health effects of green tea. 
Citation: Mahboub FA (2016) The Effect of Green Tea (Camellia sinensis) Extract Against Hepato-Toxicity Induced By Tamoxifen in Rats. J Food Process Technol 7: 625. doi: 10.4172/2157-7110.1000625

\section{References}

1. Scalbert A, Johnson I, Saltmarsh M (2005) Polyphenols: Antioxidants and beyond. Am J Clin Nutr 81: 215-217.

2. Yang C, Wang H, Li G, Yang Z, Guan F, et al. (2011) Cancer prevention by tea: evidence from laboratory studies. Pharmacol Res 64: 113-122.

3. Mei Y, Qian F, Wei D, Liu J (2004) Reversal of cancer multidrug resistance by green tea polyphenols. J Pharm Pharmacol 56: 1307-1314.

4. Beltz L, Bayer D, Moss A, Simet I (2006) Mechanisms of cancer prevention by green and black tea polyphenols. Anticancer Agents Med Chem 6: 389-406.

5. Forester S, Lambert J (2011) The role of antioxidant versus pro-oxidant effects of green tea polyphenols in cancer prevention. Mol Nutr Food Res 55: 844-854.

6. Amal S, Vidya P, Sharad M, Dipti T, Rahima P (2009) The sensitization of glioma cells to cisplatin and tamoxifen by the use of catechin. Molecul Biol Rep 36: 1181-1186.

7. Masami S, Achinto S, Hirota F (2011) Cancer New cancer treatment strategy using combination of $\mathrm{n}$ green tea catechins and anticancer drugs. Sci 102 317-323.

8. Ostrowska J, Skrzydlewska E (2006) The comparison of effect of catechins and green tea extract on oxidative modification of LDL in vitro. Adv Med Sci 51: $298-303$

9. Chisholm K, Bray B, Rosengren R (2004) Tamoxifen and epigallocatechin gallate are synergistically cytotoxic to MDA-MB-231 human breast cancer cells. Anticancer Drugs 15: 889-897.

10. Berletch J, Liu C, Love W, Andrews L, Katiyar S, et al. (2008) Epigenetic and genetic mechanisms contribute to telomerase inhibition by EGCG. J Cell Biochem, 103: 509-519.

11. Jordan VC (2003) Tamoxifen: A most unlikely pioneering medicine. Natl Rev Drug Discov 2: 205-213.

12. Caballero F, Gerez E, Oliveri L, Falcolff N, Battle A, et al. (2001) On the promoting action of tamoxifen in a model of hepatocarcinogenesis induced by p dimethylaminobenzene in CF1 mice. Int J Biochem Cell Biol 33: 681-690.

13. Williams GM, latropoulos MJ, Djordjevic MV, Kaltenberg OP (1993) The triphenylethylene drug tamoxifen is a strong liver carcinogen in the rat. Carcinogen 14: 315-317.

14. Yiannakopoulou E (2014) Interaction of green tea catechins with breast cancer endocrine treatment. Pharmacol System Rev 94: 245-248

15. Halliwell B, Gutteridge J (2001) Detection of free radicals and other reactive species: trapping and fingerprinting. Free Radicals in Biology and Medicine, Oxford.

16. Maity S, Vadasiromoni J, Ganguly D (1998) Role of glutathione in the antiulcer effect of hot water extract of black tea. Jap J Pharmacol 78: 285-292.

17. Hard GC, latropoulos MJ, Jordan K, Radi L, Kaltenberg OP, et al. (1993) Major difference in the hepatocarcinogenicity and DNA adduct forming ability between toremifene and tamoxifen in female $\mathrm{Crl}$ : $\mathrm{CD}(\mathrm{BR})$ rats. Cancer Res 53: 4534-4541.

18. Tappel A (1978) Glutathione peroxidase and hydroperoxides. Methods Enzymo 11: $506-513$.

19. Clairborne A (1985) Catalase activity. Handbook of methods for oxygen radical research, CRC press, Boca Raton, USA

20. Kakkar P, Das B, Viswanathan P (1984) A modified method for assay of superoxide dismutase. Ind J Biochem Biophys 21: 131-132.

21. Ohkawa H, Ohishi N, Yagi K (1979) Assay for lipid peroxidation in animal tissues by thiobarbituric acid reaction, Annal Biochem 95: 351-358.

22. Bancroft D, Gamble M (2002) The theory and practice of histological technique (5thedn). Churchill Living Stone.

23. Howell D (1995) Fundamental statistics for the behavioral sciences (3rdedn) Duxbury press. An imprint of Wads Worth publishing company Belmont, California.

24. Lee I, Shiroma E, Lobelo F, Puska P, Blair S, et al. (2012) Effect of physical activity on major non communicable disease and life expectancy. Lancet 380 219-229.
25. Desai P, Nallani S, Sane R, Moore L, Goodwin B, et al. (2002) Induction of cytochrome P450 3A4 in primary human hepatocytes and activation of the human pregnant $\mathrm{X}$ receptor by tamoxifen and 4-hydroxy tamoxifen. Drug Metab Dispos 30: 608-612.

26. Hellmann-Blumberg U, Taras TL, Wurz GT, DeGreorio MW (2000) Genotoxic effects of the novel antiestrogenic FC-1271a in comparison to tamoxifen and toremifene. Breast Cancer Res Treat 60: 63-70.

27. Seven A, Güzel S, Seymen O, Civelek S, Bolayirh M, et al. (2004) Effects of vitamin $\mathrm{E}$ supplementation on oxidative stress in streptozotocin induced diabetic rats: Investigation of liver and plasma. Yonsei Med J 45: 703-710.

28. Tarek-Heikal M, Abdel-Tawab H, Mossa P, Gehan I, Marei KH, et al. (2012) Cyromazine and Chlorpyrifos Induced Renal Toxicity in Rats: The Ameliorating Effects of Green Tea Extract. J Environ Anal Toxicol 6: 48-55

29. Palomero J, Galan AI, Munoz ME, Tunon MJ, Gonzalez- Gallego J, et al. (2001) Effects of aging on the susceptibility to the toxic effects of cyclosporine A in rats Changes in liver glutathione and antioxidant enzymes. Free Rad Biol Med 30: 836-845.

30. El-Beshbishy HA (2005) Hepatoprotective effect of green tea (Camellia sinensis) extract against tamoxifen-induced liver injury in rats. J Biochem Mol Biol 38: 563-570.

31. Mansour S, Mossa A (2010) Oxidative damage, biochemical and histopathological alterations in rats exposed to chlorpyrifos and the antioxidant role of zinc. Pest Bioch Physiol 96: 14-23.

32. Halliwell B (2008) Are polyphenols antioxidants or pro-oxidants? What do we learn from cell culture and in vivo studies? Arch. Biochem Biophys 476 107-112.

33. Iqbal M, Giri U, Giri D, Alam M, Athar M (1999) Age-dependent renal accumulation of 4-hydroxy-2-nonenal (HNE)-modified proteins following parenteral administration of ferric nitrilotriacetate commensurate with its differential toxicity: Implications for the involvement of HNE-protein adductsin oxidative stress and carcinogenesis. Arch Biochem Biophys 365: 101-112.

34. Heikal T, Ghanem H, Soliman M (2011) Protective effect of green tea extracts against dimethoate induced DNA damage and oxidant/antioxidant status in male rats. Biohealth Science Bulletin 3: 1-11.

35. Akcay T, Dinner Y, Kayali R, Colgar U, Oral E, et al. (2000) Effects of hormone replacement therapy on lipid peroxides and oxidation system in postmenopausal. women J Toxicol Environ Health 59: 1-5.

36. Hesham A (2005) Hepatoprotective effect of green tea (Camellia sinensis) extract against tamoxifen-induced liver injury in rats. J Biochem Molecul Biol 38: $563-570$.

37. Chung S, Joshua D, Shengmin S (2009) Anti-oxidative and anti-carcinogenic activities of tea polyphenols. Arch Toxicol 83: 11-21.

38. Skryzdlewska E, Ostrowska J, Stankiewicz A, Fabisszewski R (2002) Green tea as a potent antioxidant in alcohol intoxication. Add Biol 7: 307-314

39. Cui Y, Kim D, Park K (2005) Antioxidant effect of Inonotus obliqus. J Ethnopharmacol 96: 79-85.

40. Paquay J, Haenen G, Stender G, Wiseman S, Tijburg L, et al. (2000) Protection against nitric oxide toxicity by tea. J Agri Food Chem 48: 5768-5772.

41. Oge A, Sezer ED, Ozgonul M, Bayraktar F, Sozmen EY (2003) The effects of estrogen and raloxifene treatment on the antioxidant enzymes and nitritenitrate levels in brain cortex of ovarictomized rats. Neurosci 338: 217-220.

42. Gonzalez E, Rosello-Catafau J, Jawerbaum A, Sinner D, Pustovrh C, et a (2000) Pancreatic nitric oxide and oxygen free radicals in the early stages of streptozotocin induced diabetes mellitus in the rat. Braz Med Biol Res 33: 13351342.

43. Cabrera C, Artacho R, Gimenez R (2006) Beneficial effects of green tea-a review. J Am Coll Nutr 25: 79-99.

44. Messarah M, Saoudi M, Boumendjel A, Kadeche L, Boulakoud MS, et al. (2013) Green tea extract alleviates arsenic-induced biochemical toxicity and lipid peroxidation in rats. Toxicol Ind Health 29: 349-359.

45. Gao FF, Wei LJ, Wang Y, Fan R, Li Q, et al. (2016) Tamoxifen induces hepatotoxicity and changes to hepatocyte morphology at the early stage of endocrinotherapy in mice. Biomed Rep 4: 102-106. 